\title{
Một trăm ngày có lẻ của ông Phạm Minh Chính trên cương vị Thủ tướng
}

\author{
Huỳnh Phan
}

\section{Báo Xây Dựng}

Ngày 27 tháng 7 năm 2021

https://baoxaydung.com.vn/mot-tram-ngay-co-le-cua-ong-pham-minh-chinh-tren-cuong-vi-thu-tuong$\underline{310876 . h t m l}$

(Xây dựng) - Ngày 26/7, ông Phạm Minh Chính, lần thứ hai trong vòng hơn 100 ngày có lẻ, đã tuyên thệ nhậm chức Thủ tướng. Lần đầu ông làm điều này là ngày 5/4/2021, trong phiên họp cuối cùng của Quốc hội khóa trước, chuẩn bị cho ngày bầu cử Quốc hội khóa mới.

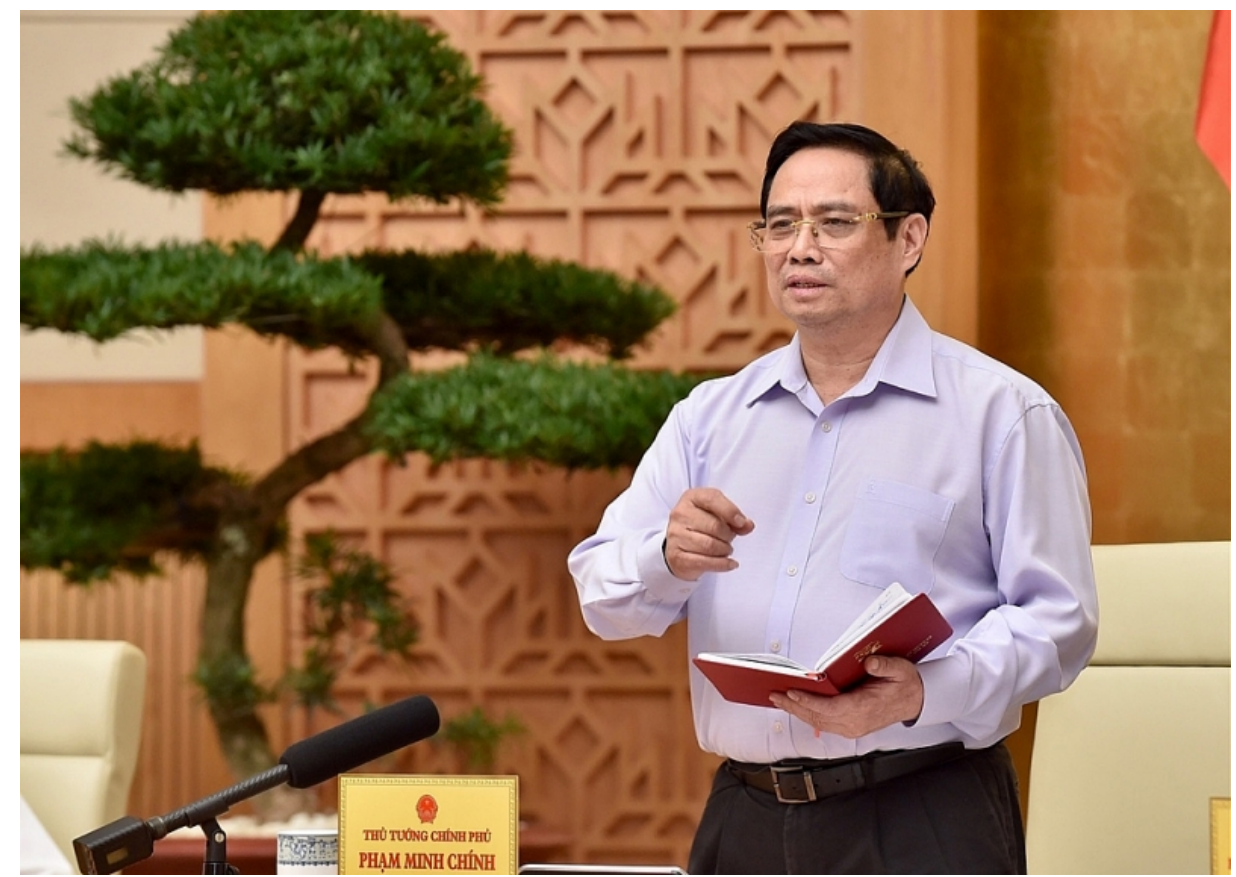

Thủ tướng Chính phủ Phạm Minh Chính.

\section{Cá nhân hóa trách nhiệm...}

PGS.TS Trần Đình Thiên, người đã viết lời bạt cho cuốn sách "Kinh tế Việt Nam - Thăng trầm và Đột phá" năm 2009, do ông Phạm Minh Chính viết cùng với một tác giả khác và là nhà tham vấn về chính sách phát triển Quảng Ninh, khi ông Phạm Minh Chính (từ năm 2011) được phân công làm Bí thư Tỉnh ủy Quảng Ninh, đã nói về hơn 100 ngày có lẻ về ông Phạm Minh Chính trên cương vị Thủ tướng.

Thứ nhất, nói về hơn ba tháng ngắn ngủi trên cương vị Thủ tướng, ông Phạm Minh Chính đã thể hiện tính cương quyết và hành động trong vai trò chống dịch Covid-19: "Khi các biện pháp chống dịch kiểu truyền thống như truy vết, hoặc cách ly, đã không còn nhiều hiệu lực nữa, ông Phạm Minh Chính và 
Chính phủ Việt Nam đã kiên quyết chuyển sang tìm các nguồn vắc-xin bên ngoài, và đến nay chúng ta đã có các nguồn vắc-xin của $M y ̃$, của Nhật, hay của Úc và đang xúc tiến nhanh việc sản xuất vắc-xin Sputnik $V$ của Nga, cũng như xúc tiến việc sản xuất vắc-xin của Việt Nam", PGS.TS Trần Đình Thiên nói.

Thứ hai, theo PGS.TS Trần Đình Thiên, Chính phủ dưới sự lãnh đạo của Thủ tướng Phạm Minh Chính đã kiên quyết giảm hơn 1.000 dự án không hiệu quả trong số hơn 6.000 dự án trên cả nước.

“Đây là quyết định đột phá, vì xưa nay việc cắt giảm dính đến các ngành, các địa phương, và nhất là dính đến các nhóm lợi ích. Trong khi đó, trong bối cảnh dịch Covid đang gây hậu quả rất cao ở nước ta, không chỉ về sức khỏe người dân mà còn ảnh hưởng rất lớn đến sản xuất kinh doanh, quyết định này rõ ràng đã dành nguồn tài lực cho những ưu tiên cần thiết", PGS.TS Trần Đình Thiên khẳng định.

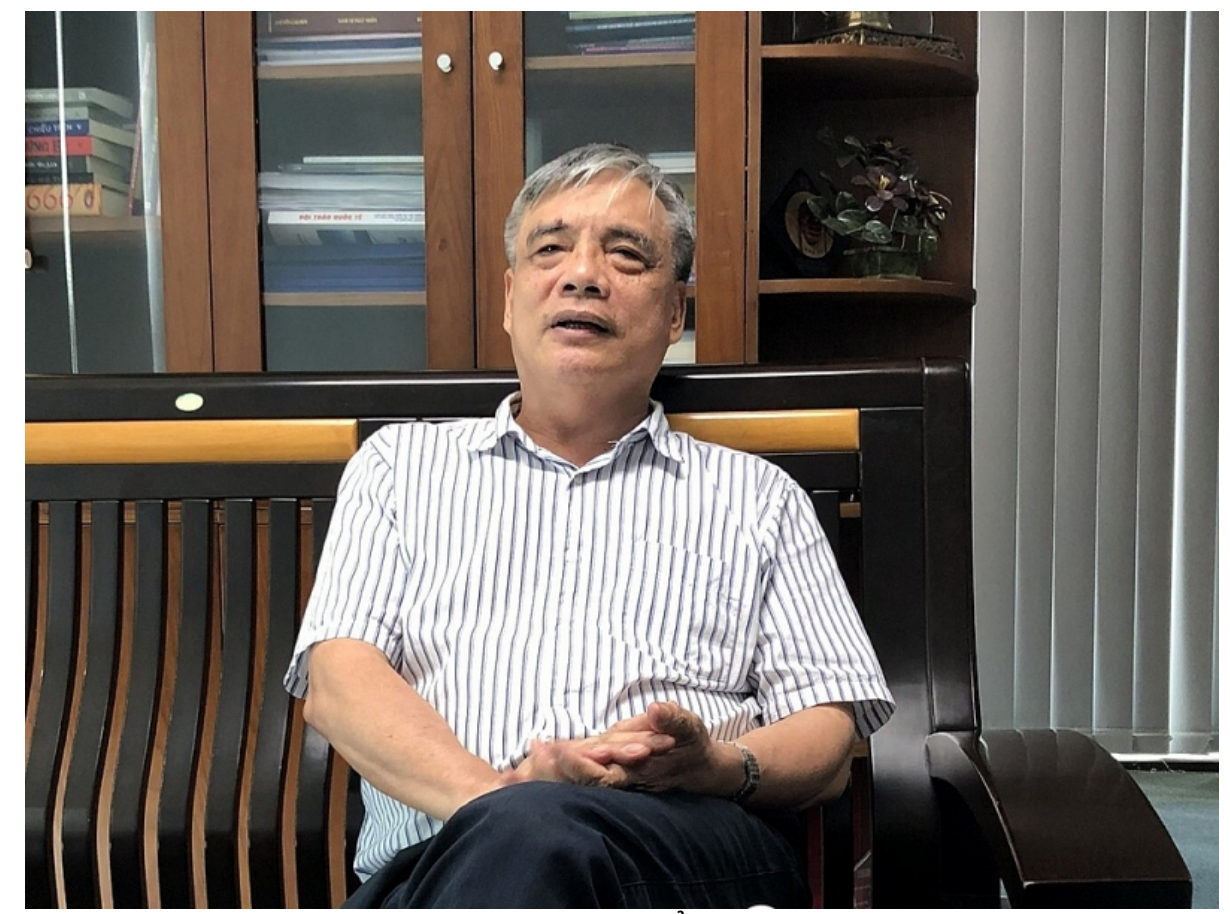

PGS.TS Trần Đình Thiên (Ảnh: Huỳnh Phan)

Thứ ba, PGS.TS Trần Đình Thiên đánh giá rất cao lời phát biểu của Thủ tướng Phạm Minh Chính về "cá nhân hóa trách nhiệm”: “Quen nhiều với ông Phạm Minh Chính, khi ông còn làm Bí thư Quảng Ninh, tôi đoán ông Chính không dừng lại ở đó, mà còn nghĩ ra bài bản để bảo vệ những cá nhân có những sáng kiến mà ban đầu người ta có thể coi là "phạm luật", vì đi trước thể chế. Đó có thể là những cải cách về thể chế trong thời đại Thủ tướng của ông".

\section{Một Thủ tướng vừa có tầm nhìn xa, vừa ngăn nắp trong hành động hàng ngày}

TS. Vương Quân Hoàng, Giám đốc Trung tâm Nghiên cứu Khoa học Xã hội Liên ngành (ISR), Đại học Phenikaa, chính là đồng tác giả cuốn "Kinh tế Việt Nam - Thăng trầm và Đột phá" cùng ông Phạm Minh Chính. Hai người cũng là đồng tác giả cuốn sách “"Bối cảnh tài chính Việt Nam 1997 - 1998 và 2007 2008: Khoảng cách và biến đối", xuất bản trước đó một năm. 
Khoảng giữa năm 2011, người viết có hỏi TS. Vương Quân Hoàng, khi biết về tác giả hai cuốn sách này, rằng vì sao "ông lại viết sách chung với ông Phạm Minh Chính, lúc đó đang là sĩ quan công an"? TS. Vương Quân Hoàng hài hước trả lời: "Đôi bạn cùng tiến mà."

Sau đó, dường như hai đồng tác giả này lại đi theo hai con đường hoàn toàn khác nhau.

Ông Phạm Minh Chính tiếp tục con đường chính trị của mình. Ông làm Bí thư Tỉnh ủy Quảng Ninh, Trưởng ban Tổ chức Trung ương và rồi làm Thủ tướng Chính phủ.

Trong khi đó, TS. Vương Quân Hoàng tập trung nhiều thời gian vào việc chinh phục việc nghiên cứu trong lĩnh vực khoa học xã hội, ở tầm vóc quốc tế. Hơn 150 bài báo quốc tế mà hoặc ông viết, hoặc đứng tên với tư cách người dẫn dắt tư tưởng, đều đạt tiêu chuẩn ISI/Scopus. Đặc biệt, 10 bài báo đứng tên ông được đăng trên Tạp chí Khoa học nổi tiếng hàng đầu thế giới Nature.

TS. Vương Quân Hoàng là một trong những chuyên gia mà Bí thư Quảng Ninh Phạm Minh Chính thường tham khảo ý kiến, mỗi khi gặp vấn đề hóc búa trong chiến lược phát triển Quảng Ninh. Đến khi Thủ tướng Phạm Minh Chính chuẩn bị nhậm chức, xuất hiện bài viết trên Báo Tuổi trẻ (Thành phố Hồ Chí Minh) ngay buổi sáng 5/4/2021, cũng của TS. Vương Quân Hoàng, về những thách thức và những việc cần làm của Chính phủ mới.

Khi người viết hỏi TS. Vương Quân Hoàng về 100 ngày có lẻ của Thủ tướng Phạm Minh Chính, ông trả lời rằng, trước nhiệm kỳ này, thường các Thủ tướng phải mất cả năm mới làm quen được với các thành viên Chính phủ. “Ông Phạm Minh Chính chỉ trong 100 ngày có lẻ đã triển khai được những việc cần làm, bởi những lý lẽ dưới đây" - TS. Vương Quân Hoàng nói.

Thứ nhất, về cách tổ chức Chính phủ dưới thời Thủ tướng Phạm Minh Chính, theo TS. Vương Quân Hoàng, là được xây dựng có tư tưởng và hành động nhất quán, chứ không vì tình huống này mà phát sinh ra chương trình kia. "Các chương trình, đề xuất của ông đều được nêu ra trước Chính phủ, cùng bàn bạc, và mọi thành viên Chính phủ cứ theo đó mà thực hiện", TS. Vương Quân Hoàng nói.

TS. Vương Quân Hoàng nói thêm: “Đó là một con người rất ngăn nắp trong suy nghĩ và hành động, bởi khi làm những chuyện lớn như "cầm cân nảy mực" một nền kinh tế quốc gia mà không ngăn nắp, để chuyện nọ xọ chuyện kia, sẽ rất nguy hiểm. Lúc đó, chuyện đáng làm thì mình không làm, mà lại mất công làm những chuyện chưa đáng làm, hoặc không đáng làm."

Điều thứ hai mà TS. Vương Quân Hoàng nhận xét ở 100 ngày của Tân Thủ tướng là ông Phạm Minh Chính không đưa ra nhiều điều về trách nhiệm, hay khả năng kiến tạo, nhưng trong cách hành động ông tỏ ra khá gương mẫu trong hành động, và bám sát các điểm nóng.

TS. Vương Quân Hoàng dẫn ra câu chuyện vải thiều ở Hưng Yên. "Câu chuyện vải chín chỉ kéo dài 3 tuần thôi, không giải quyết xong coi như mất mùa. Lúc đó container còn thiếu, phương tiện vận tải gặp vấn đề, thế mà Chính phủ của ông Phạm Minh Chính đã giải quyết xong, bằng cả thị trường trong nước lẫn thị trường nước ngoài, như Nhật, hay châu Âu" (TS. Vương Quân Hoàng dẫn). 
“Phải là người rất chăm, và có phương pháp làm việc, mới bắt cả hệ thống chính trị vào cuộc một cách nghiêm túc như vậy.

Điểm thứ ba, rất quan trọng, là Thủ tướng Phạm Minh Chính tuy bám sát nhiều sự việc, nhưng ông rất tập trung vào những sự việc quan trọng với nền kinh tế quốc gia, TS. Vương Quân Hoàng nhận xét. "Đã có những thông điệp về kiểm soát vĩ mô và lạm phát, đó là những việc thường trực phải quan tâm, mặc dù có những việc phòng chống dịch bệnh được coi là cấp bách hơn".

“Ví dụ, họp Chính phủ xong, bên Ngân hàng Nhà nước phải họp ngay để bàn và triển khai những điều Chính phủ quyết định. Những điều lãnh đạo Ngân hàng Nhà nước quyết định đều được đăng báo, và Thủ tướng và cử tri, cũng như báo chí, cứ thế mà theo dõi, giám sát. Tôi có thể nói đó là sự giám sát thật, vì mọi chuyện đã được ghi rõ trong biên bản", TS. Vương Quân Hoàng tiếp tục diễn giải.

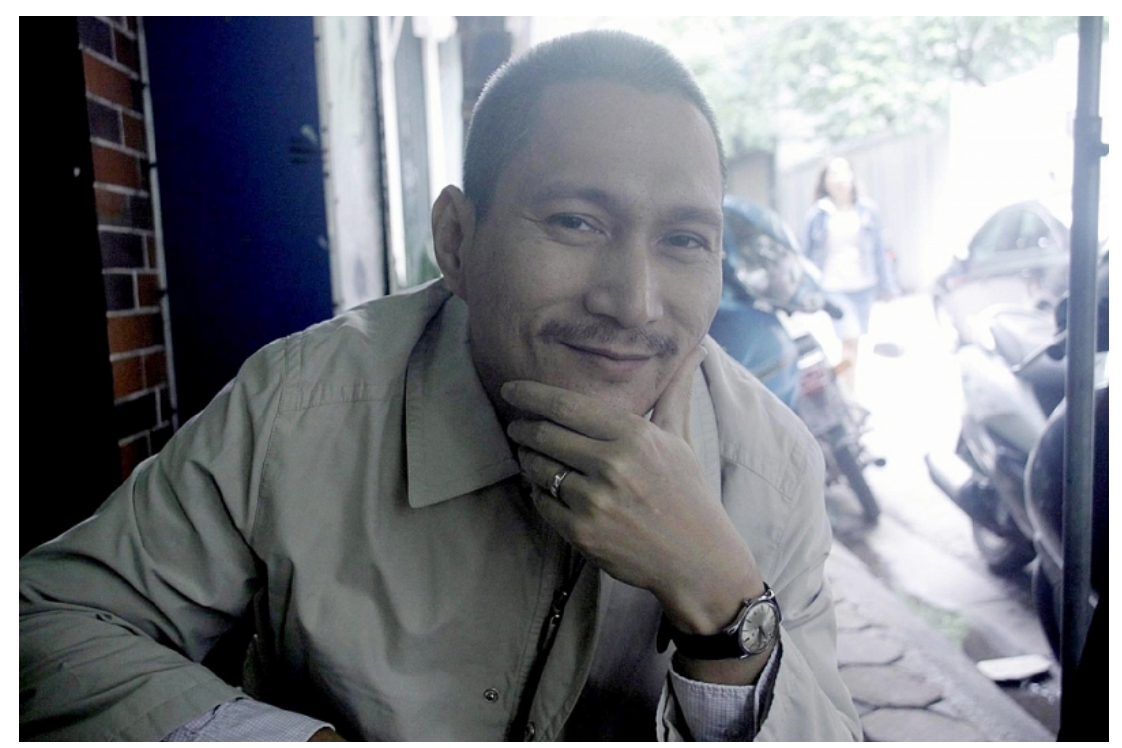

TS. Vương Quân Hoàng (ảnh: Huỳnh Phan)

“Cứ như vậy, mỗi bộ trong phiên họp Chính phủ phải tự nghĩ ra những việc mà bộ mình đang đối mặt, và tự trình lên Thủ tướng. Bởi nếu không phát hiện ra, nếu Thủ tướng tìm ra, lần sau họp Chính phủ, Thủ tướng nhắc tới thì tự nhiên thấy ngượng, và phải sửa đổi ngay lập tức", TS. Vương Quân Hoàng hóm hỉnh nhận xét.

“Qua trăm ngày có lẻ của Thủ tướng Phạm Minh Chính trên cương vị đó, tôi có thể nhận xét rằng Việt Nam đang có một Chính phủ làm việc, và ngày càng tích cực hơn, tuy có nhiều điều vẫn phải tiếp tục tự sửa sai", TS. Vương Quân Hoàng kết luận.

\section{Huỳnh Phan}




\section{Sự kiện \& Bình luận}

\begin{tabular}{|c|c|c|}
\hline MớI NHẤT & Môt trăm ngày có lẻ của ông Pham & QUAN TÂM NHIỀU/ \\
\hline TÁC GIẢ & Minh Chính trên cương vị Thủ tướng & $\begin{array}{l}\text { Nâng cao kiến thức pháp luật để } \\
\text { người dân thoát khỏi nỗi sơ vô }\end{array}$ \\
\hline Bùi Văn Doanh & (1) $10: 46$ | 27/07/2021 & hình \\
\hline Kim Quốc Hoa & thứ hai trong vòng & \\
\hline Lưu Bình Nhưỡng & ầu ông làm & Sự hồn nhiên đến cạn lời về "văn \\
\hline Lưu Đức Cường & $\begin{array}{l}\text { điêu nảy là ngáy 5/4/2021, trong phiên họp cuôi cúng cúa Quốc hội khóa } \\
\text { trước, chuẩn bị cho ngày bầu cử Quốc hội khóa mới. }\end{array}$ & noa Knon 101 \\
\hline Nguyễn Hoàng Linh & & $\begin{array}{l}\text { Thanh Hóa: Khô cho cô giáo, khó } \\
\text { cho học sinh lớp } 1\end{array}$ \\
\hline Phạm Gia Yên & & Kim Quốc Hoa \\
\hline Phạm Thanh Tùng & & Tổng lực cho TP.HCM dập dịch \\
\hline Đào Hồng Tuyển & & Kim Quốc Hoa \\
\hline Đỗ Quang Đán & & $\begin{array}{l}\text { Một trăm ngày có lẻ của ông } \\
\text { Phạm Minh Chính trên cương vị } \\
\text { Thủ tướng }\end{array}$ \\
\hline
\end{tabular}

*Nguồn: https://baoxaydung.com.vn/mot-tram-ngay-co-le-cua-ong-pham-minh-chinh-tren-cuong-vithu-tuong-310876.html (ngày truy cập: 27/7/2021) 